\title{
Pigeons' spatial memory: V. Proactive interference in the delayed matching of key location paradigm occurs only under restricted conditions
}

\author{
DONALD M. WILKIE \\ University of British Columbia, Vancouver, British Columbia, Canada
}

\begin{abstract}
In the delayed matching of key location procedure, pigeons must remember the location of the sample key in order to choose correctly between two comparison keys. The deleterious effect of short intertrial intervals on key location matching found in previous studies suggested that pigeons' short-term spatial memory is affected by proactive interference. However, because a reward expectancy mechanism may account for the intertrial interval effect, additional research aimed at demonstrating proactive interference was warranted. In Experiment 1, matching accuracy did not decline from early to late trials within a session, a finding inconsistent with a proactive interference effect. In Experiment 2, evidence suggestive of proactive interference was found: Matching was more accurate when the locations that served as distractors and as samples were chosen from different sets. However, this effect could have been due to differences in task difficulty, and the results of the two subsequent experiments provided no evidence of proactive interference. In Experiment 3, the distractor on Trial $n$ was either the location that had served as the sample on Trial $n-1$ or one that had been a sample on earlier trials. Matching accuracy was not inferior on the former type of trial. In Experiment 4, the stimuli that served as samples and distractors were taken from sets containing 2,3,5, or 9 locations. Matching accuracy was no worse, actually slightly better, with smaller memory set sizes. Overall, these findings suggested that pigeons' memory for spatial location may be immune to proactive interference. However, when, in Experiment 5, an intratrial manipulation was used, clear evidence of proactive interference was found: Matching accuracy was considerably lower when the sample was preceded by the distractor for that trial than when it was preceded by the sample or by nothing. Possible reasons why interference was produced by intratrial but not intertrial manipulations are discussed, as are implications of these data for models of pigeons' short-term spatial memory.
\end{abstract}

Delayed matching of key location is a useful paradigm for the study of pigeons' short-term retention of spatial location information (e.g., Wilkie, 1983a, 1983b, 1984; Wilkie \& Summers, 1982; see also Smith, Attwood, \& Niedorowski, 1982). Nine pecking keys, arranged as a $3 \times 3$ matrix, serve as the spatial cues. One randomly selected key is lit briefly as a sample. After a short delay (i.e., retention interval), the sample key is lit again along with a randomly selected nonsample key. A peck to the sample key produces grain reinforcement, whereas a peck to the distractor key leads directly to the intertrial interval, which typically lasts about $20 \mathrm{sec}$. When the delay interval is on the order of a few seconds, pigeons accurately choose the matching location.

Pigeons' short-term memory for key location is resistant to retroactive interference resulting from the presentation of certain types of events during the retention in-

This research was supported by the Natural Sciences and Engineering Research Council of Canada. R. Wright, R. Takai, D. Kennedy, $K$. Arbour, and S. Kardal assisted with the research. Requests for reprints may be sent to Donald M. Wilkie, Psychology Department, The University of British Columbia, Vancouver, B.C., Canada V6T 1Y7 terval. Wilkie (1983b, Experiment 1) found that a change in ambient illumination produced by turning on the houselight did not affect key location matching accuracy. This lack of interference stands in contrast to the usual strong, deleterious effect of such stimuli in other short-term memory paradigms (e.g., Wilkie, Summers, \& Spetch, 1981). Similar results have been reported by Olson and Maki (1983) for pigeons tested in a delayed alternation paradigm: Pigeons' choice of the arm of the T-maze opposite to the one to which they were first forced was unaffected by illumination change during the interval between forced and free choice. Pigeons' memory for key location is not completely immune from retroactive interference, however. Wilkie (1983b, Experiment 2), for example, found that brief presentation of the distractor key during the retention interval adversely affected matching.

Evidence that previously stored information (i.e., proactive interference) might affect pigeons' accuracy of key location matching as it does radial-arm maze performance (Roberts \& Van Veldhuizen, 1985) also has been found. Wilkie (1984) found that matching accuracy was lower when the intertrial interval (ITI) was $2.5 \mathrm{sec}$ than when 
it was $25 \mathrm{sec}$, a finding that suggested that residual information from the previous trial interfered with correct matching. However, because ITI manipulations may affect processes other than memory, it is important that other manipulations be used in attempts to detect proactive interference. For example, Roberts and Kraemer (1982) and Wilkie (1984) suggested that ITI length may affect expectancy of reward (Brodigan \& Peterson, 1976) during the trial and, accordingly, the care with which the matching response is made. In the present report, the results of other tests for proactive interference are presented.

\section{EXPERIMENT 1}

One manifestation of proactive interference is that performance deteriorates as a function of the amount of previous information that has been stored. Thus, in the delayed matching of key location paradigm, in which pigeons are required to remember the sample key location on each trial, one would expect matching accuracy to deteriorate across trials if pigeons' memory for location is affected by proactive interference. The purpose of the present experiment was to measure matching accuracy over blocks of trials within a session and ascertain if matching accuracy declined.

\section{Method}

Subjects. Five King pigeons were maintained at about $90 \%$ of their free-feeding weights by mixed grain obtained during and after test sessions. All birds had had previous delayed matching of key location training.

Apparatus. The test chambers have been described in detail previously (e.g., Wilkie, 1984). Briefly, the chambers contained a grain feeder and a $3 \times 3$ matrix of pecking keys. Behind each key were a microswitch, which detected pecks, and a red-light-emitting diode. From the pigeons' perspective, the keys were numbered as follows:

$$
\begin{array}{lll}
3 & 2 & 1 \\
6 & 5 & 4 \\
9 & 8 & 7
\end{array}
$$

Data collection and experimental control were carried out by a Data General NOVA 3 computer operating under RDOS and the MANX language (Gilbert \& Rice, 1979).

Procedure. Because the pigeons had been trained previously to match key location, no preliminary training was necessary. The subjects received 14 sessions, each of which consisted of 40 trials. The ITI was $20 \mathrm{sec}$, sample duration was $2 \mathrm{sec}$, and the retention interval, $1 \mathrm{sec}$. Each trial was signaled by a $1-\mathrm{sec}$ operation of the grain feeder. Correct choices were rewarded with 5 -sec access to the feeder. Matching accuracy was recorded for Trials 1 to 5, 6 to 10 , and so forth.

\section{Results and Discussion}

Matching accuracy did not change systematically from the start to the end of the session. Figure 1 shows matching accuracy for blocks of five trials for each subject as well as the average across all pigeons.

These results provide no evidence for proactive interference in pigeons' short-term spatial memory.

\section{EXPERIMENT 2}

Because, in delayed matching tasks, the stimuli that serve as samples and distractors are chosen from the same set, a stimulus that had served as a sample on Trial $n-1$ (and rewarded if chosen) may appear as the distractor on Trial $n$; proactive interference may result from confusion over which stimulus had appeared most recently as the sample. This would not happen if the stimuli that served as samples and as distractors came from different sets. The purpose of the present experiment was to determine if matching accuracy was higher when sample keys never appeared as distractor locations.

\section{Method}

Subjects and Apparatus. Three King pigeons, maintained at about $90 \%$ of their free-feeding weights, were tested in the apparatus employed in Experiment 1.

Procedure. Because the pigeons had been trained previously to match key location, no preliminary training was required. The experiment consisted of two phases, both of which were replicated. In the first phase, the key locations that served as samples and distractors came from different sets (the DS condition). In the second phase, the keys came from the same set (the SS condition). These phases lasted six sessions; both replications lasted five sessions.

In both conditions, the 60 trials in a session were separated by a 30-sec ITI. At the start of each session of both conditions, one of four sets of six stimuli was chosen randomly. In the DS condition, the four sets consisted of the following keys: $(1,6,7,2,4,8)$, $(2,4,8,1,5,9),(3,6,9,2,5,8)$, and $(5,6,8,1,2,9)$. In the SS condition, the sets were: $(2,4,5,2,4,5),(1,5,9,1,5,9)$, $(3,6,7,3,6,7)$, and $(2,6,8,2,6,8)$. Note that the first three members of the DS sets are different from the last three members (e.g., 1, 6, 7, 2, 4, 8), whereas the first three members of the SS sets are the same as the last three members (e.g., 2, 4, 5, 2, 4, 5). At the start of a trial, one of the first three members of a set was chosen randomly (with replacement) as a sample, which was presented for $2 \mathrm{sec}$ and followed by a 2 -sec retention interval. On each trial, one of the keys from the second three members was randomly selected as a distractor. (In the SS condition, the distractor was always one of the two nonsample stimuli.) This sampling procedure permitted the same stimulus to appear as the sample on Trial $n-1$ and as the distractor on Trial $n$ in the SS, but not the DS, condition.

\section{Results and Discussion}

Matching accuracy was consistently higher in the DS condition as shown in Figure 2. This difference was confirmed in a two-factor (condition and replication) repeated measures analysis of variance. Accuracy in the DS condition (mean $=72.3$ ) was significantly higher than that in the SS condition (mean $=63.8)[F(1,2)=32.1$, $p<.05]$. Neither the replication $[F(1,2)=7.0, p=.12]$ nor the interaction $[F(1,2)=.53, p>.05]$ was significant.

Poorer matching by the subjects in the SS condition is suggestive of proactive interference produced by the appearance of confusing stimuli as rewarded samples on one trial and as nonrewarded distractors on later trials. This conclusion obviously stands in contrast to that reached as the result of the first experiment. This discrepancy sug- 
BIRD 1

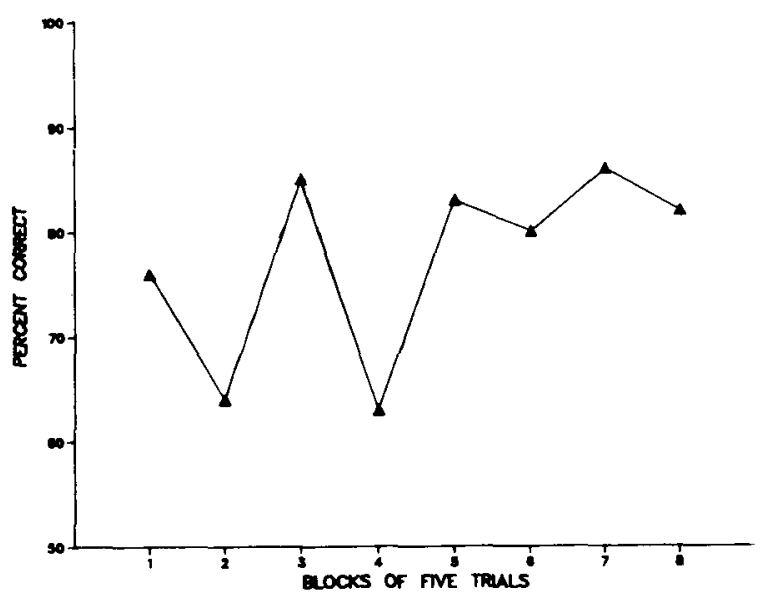

BPD 2

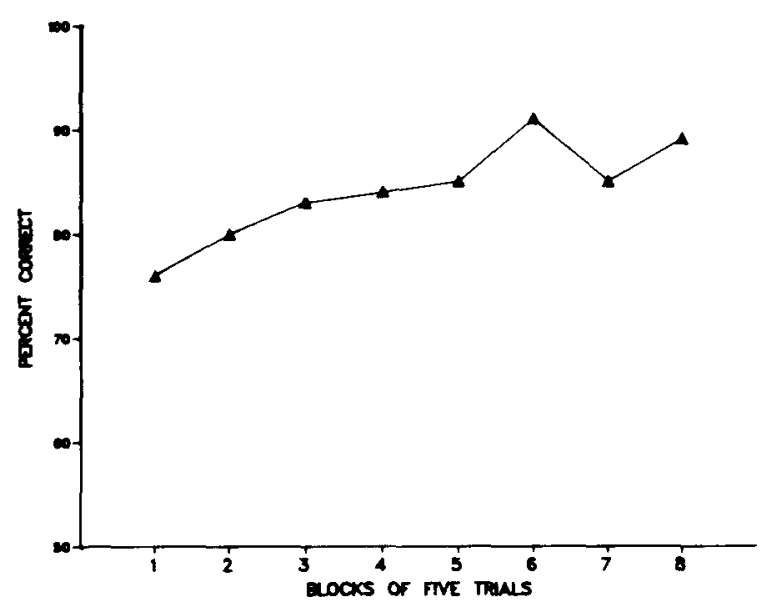

BRD 3

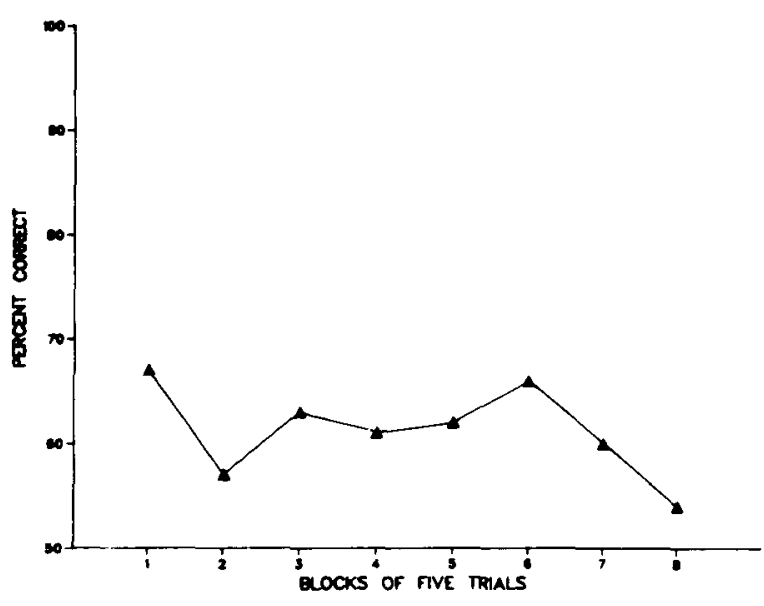

BIRD 4

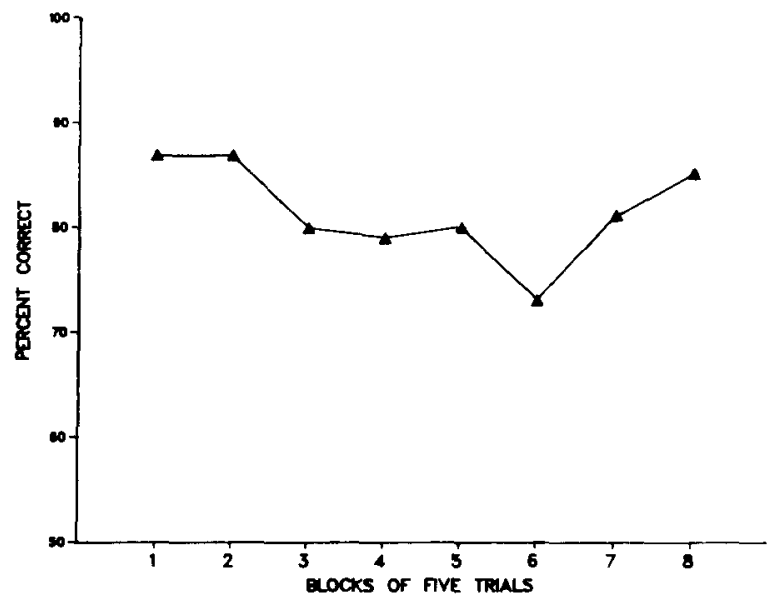

BIRD 5

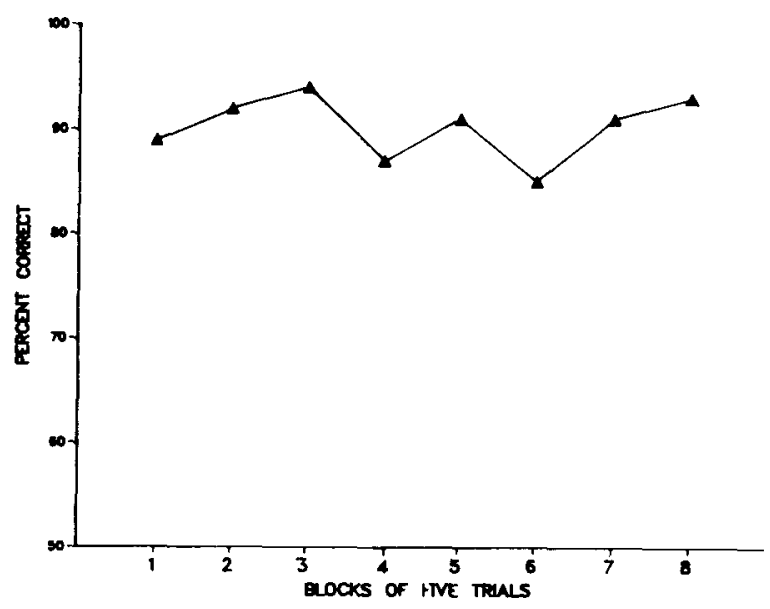

AVERAGE

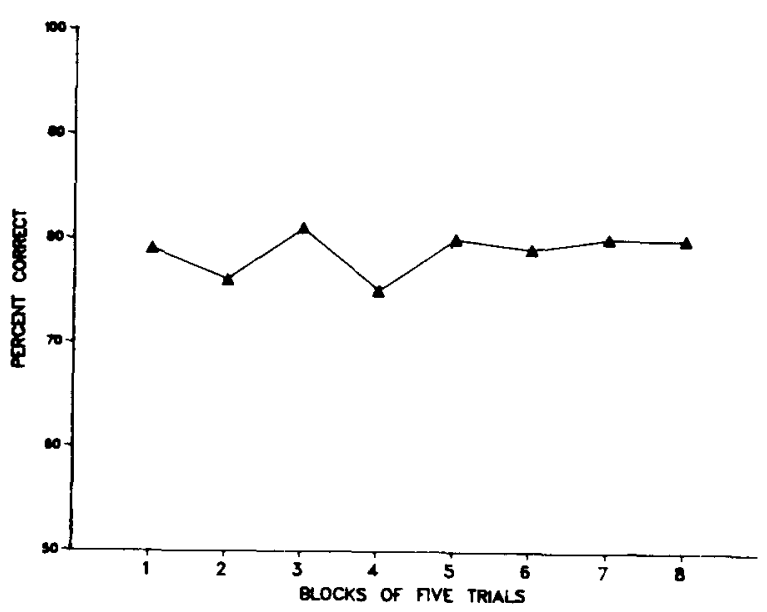

Figure 1. Matching accuracy for each pigeon for eight five-trial blocks within a session. Data are averages of all sessions. 

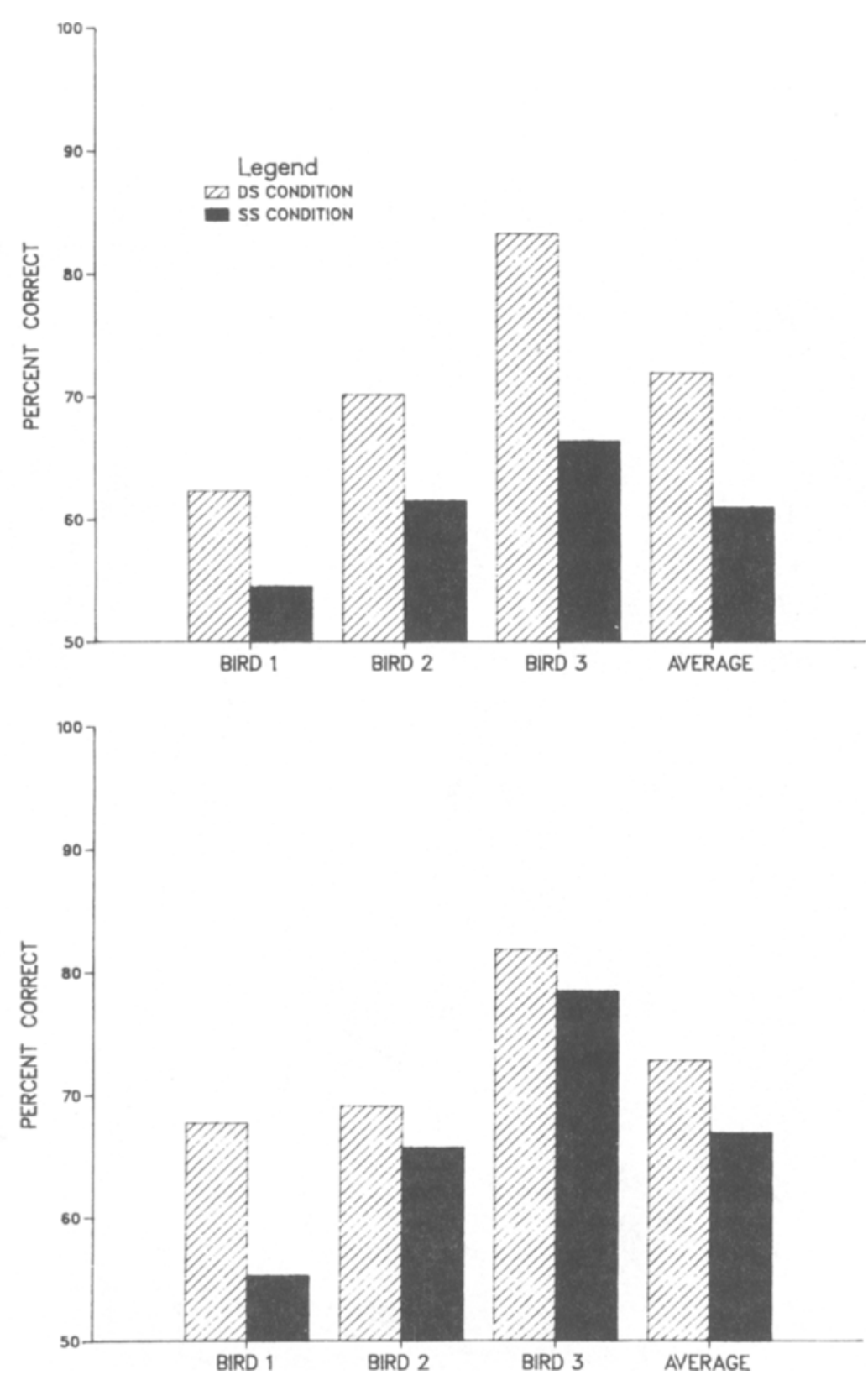

Figure 2. Matching accuracy for each pigeon in DS and SS conditions in both the original experiment (top panel) and the replication (bottom panel). Data are averages of all sessions in a phase.

gested that additional tests for proactive interference should be conducted. Also, it is possible that these results are due to nonmemory processes. Although superior matching in the different-set condition could have been due to the absence of confusion over which locations had occurred most recently, it is also possible that the different-set condition may have been a simpler, and therefore easier, task. Because the distractor locations were never rewarded, the pigeons may have learned that the other comparison sitmulus-regardless of its locationmust be correct. This point may be made clearer by con- sidering an analogous color matching procedure. If the samples are red and green and if yellow sometimes appears as a choice with either red or green, simply learning to avoid choosing yellow should facilitate "matching" accuracy.

\section{EXPERIMENT 3A}

When all nine key locations serve as potential samples and distractors, more proactive interference may occur when the distractor on Trial $n$ was the sample on 
Trial $n-1$ than when the distractor was the sample on an earlier trial. For example, assume that Key 1 was the sample and Key 7 the distractor on Trial $n-2$ and that Key 5 was the sample and Key 3 the distractor on Trial $n-1$. More interference due to the confusion over which key location had appeared most recently as the sample may be expected when the distractor on Trial $n$ is Key 3 than when it is Key 1 . In the present experiment, we compared matching accuracy on trials on which the distractor was the sample on the previous trial with accuracy on trials on which the distractor had been a component in earlier trials in the session.

\section{Method}

Subjects and Apparatus. Eight pigeons that had participated in previous delayed matching of location experiments served as subjects. The apparatus was similar to that used in the earlier experiments.

Procedure. Five pigeons (Birds 1 to 5) participated in the original experiment, and three (Birds 6 to 8 ) participated in a systematic replication.

Each subject received three 12-trial sessions each day. The sessions were separated by 2 min, during which the pigeons remained in the test chamber. In each session, the keys that served as samples on the 12 trials were identical: $7,9,2,3,1,5,7,2,4,6,5$, and, on the last trial, 2 . In the replication, the keys were: 9,6 , $5,1,7,2,9,8,4,7,3$, and 5 . For all but the first trial in a session, the probability was .5 that the distractor was the stimulus that had served as the sample on the preceding trial. On the remaining trials, the distractor was a key location other than the sample location for Trial $n-1$. The delay interval was $3 \mathrm{sec}$ and the intertrial interval was $20 \mathrm{sec}$.

The subjects were tested for 33 days.

\section{Results and Discussion}

Figure 3 shows matching accuracy on trials when the distractor was the sample from the preceding trial (i.e., was an "old" sample) or was not the sample on that trial (i.e., was "new"). Contrary to the results expected had proactive interference occurred, matching accuracy on old trials was not impaired relative to that on trials on which the distractor had not occurred on the previous trial. Indeed, for seven of the eight pigeons, matching was slightly better on these trials and nearly reached statistical significance $[$ mean old $=75.4$, mean new $=71.7 ; t(6)=$ $2.33, p=.053]$.

This result clearly is inconsistent with the idea that memory for the rewarded sample on one trial interferes with performance on the next trial.

\section{EXPERIMENT 3B}

Because proactive interference in pigeons' short-term memory is sometimes manifested only at short ITIs (see Grant, 1975), it seemed possible that the apparent absence of proactive interference found in the previous experiment was due to the typical, but rather long ( $20 \mathrm{sec})$, ITI employed. This possibility was investigated in Experiment 3B; the procedures used in Experiment 3A were replicated with a short $(5-\mathrm{sec})$ ITI.

\section{Method}

Subjects and Apparatus. Four King pigeons that were experienced at delayed matching of key location were tested in the same test chambers as those used in the previous experiments.

Procedure. The procedure was identical to that used in Experiment $3 \mathrm{~A}$ except that the ITI was $5 \mathrm{sec}$ rather than $20 \mathrm{sec}$. Each subject received between 5 and 10 sessions.

\section{Results and Discussion}

As shown in Figure 4, matching accuracy on old trials again was not impaired relative to that on which the distractor had not been the sample on Trial $n-1$.

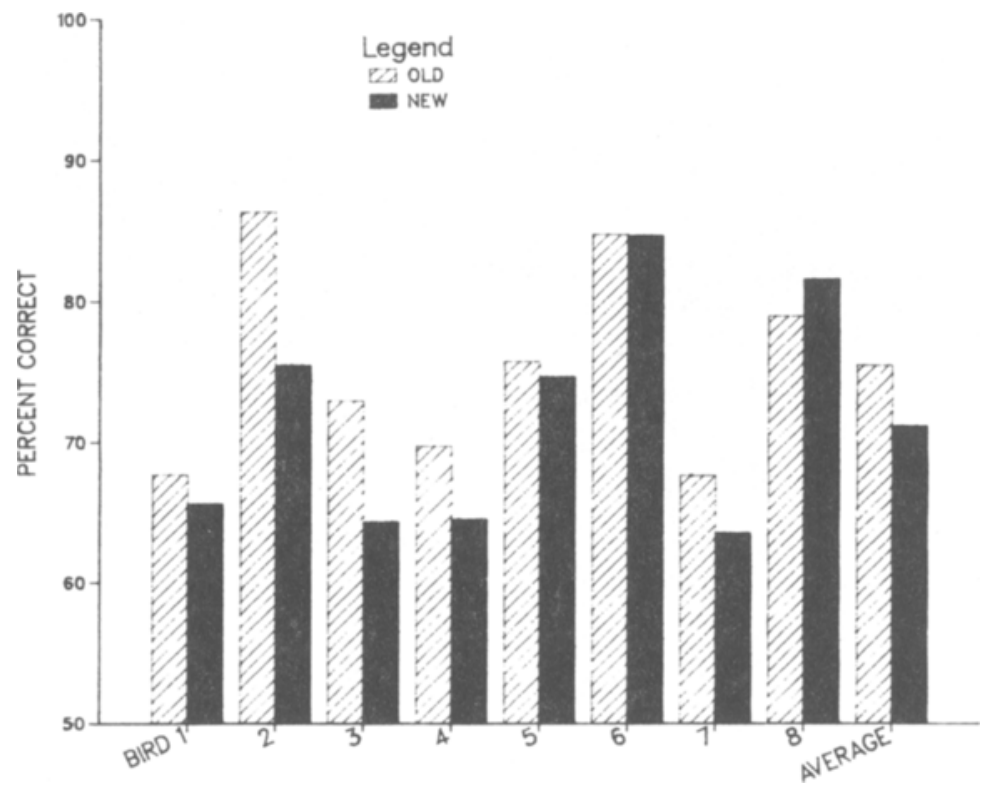

Figure 3. Matching accuracy for each pigeon when the distractor was the sample on the preceding trial (old condition) or had not been the sample on that trial (new condition). Data are averages over all sessions. 


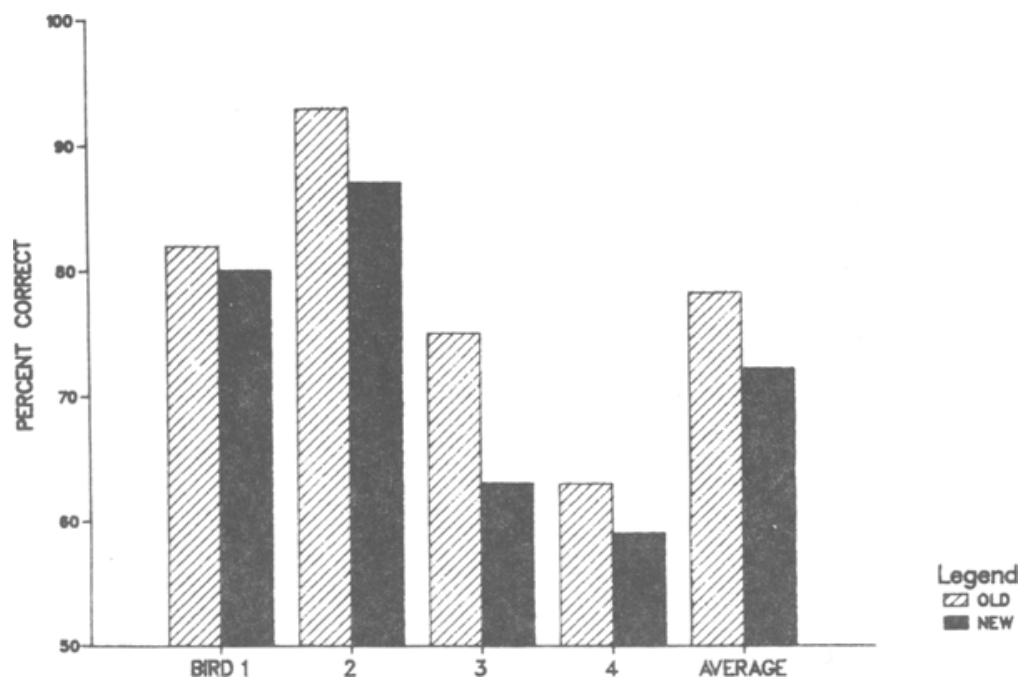

Figure 4. Matching accuracy for each pigeon when the distractor was the sample on the preceding trial (old condition) or had not been the sample on that trial (new condition). Data are averages over all sessions.

When the results of Experiments $3 \mathrm{~A}$ and $3 \mathrm{~B}$ are pooled, matching on old trials (mean $=76.5 \%$ correct) was slightly better than matching on new trials $($ mean $=72.1)$ $[t(10)=3.40, p<.01]$.

\section{EXPERIMENT 4}

Proactive interference may arise because there is confusion regarding the relative recency of the stimuli serving as samples. Therefore, matching accuracy should increase with an increase in the size of the set of available stimuli that serve as samples and distractors. With larger sets of stimuli, the occurrences of particular locations should be more widely spaced in time, on the average, and therefore they should be easier to discriminate in terms of recency. This notion has received support in an experiment in which monkeys performed delayed matching to sample with 2,3 , or 7 visual stimuli serving as the memory set (Worsham, 1975).

In the present study, memory set sizes of 2, 3, 5, and 9 locations were implemented during different test sessions. Thus, in some sessions, only 2 keys of the matrix served as sample and comparison keys; in others 3 , or 5 , or all 9 were used.

\section{Method}

Subjects and Apparatus. Three King pigeons, experienced at delayed matching of key location, were tested in the apparatus that was used in the previous experiments.

Procedure. Sessions consisted of 45 trials separated by a $15-\mathrm{sec}$ ITI. One memory set size $(2,3,5$, or 9$)$ was selected randomly at the start of each session. Then, for each memory set size except 9 , one of five groups of specific key locations was chosen at random. The groups were as follows: Set size of 2-keys numbered 1 and 3 (i.e., 1,3$),(2,8),(7,9)$, or $(2,6)$; set size of $3-(1,6$, $9),(3,2,7),(4,5,8),(1,4,7)$, or $(8,9,1)$; set size of $5-(1$, $2,6,5,8),(3,6,9,7,4),(1,2,6,5,8),(3,7,8,9,1)$, or $(6$,
$5,4,9,8$ ). Trials began with a 2 -sec illumination of a randomly chosen sample key. After a .5-sec delay, the sample and a randomly selected (except during the set size of 2 sessions) comparison were presented.

These conditions were in effect for 45 sessions.

Because proactive interference in pigeons' short-term memory sometimes occurs only at longer retention intervals (see Grant, 1975), during another 33 sessions, the delay interval was increased to $3 \mathrm{sec}$.

\section{Results and Discussion}

Figure 5 shows matching accuracy as a function of memory set size when the delay was either $.5 \mathrm{sec}$ (top panel) or $3 \mathrm{sec}$ (bottom panel). In both phases, matching accuracy declined slightly as memory set size increased. This decline is the opposite of what one would expect if proactive interference occurred and is opposite to that reported by Worsham (1975) for monkeys on a nonspatial short-term memory task.

The inverse relationship between matching accuracy and memory set size was confirmed in a phase $\times$ memory set size repeated measures analysis of variance. Memory set size was significant $[F(3,6)=7.95, p<.025]$, as was phase $[F(1,2)=518.9, p<.001]$. The memory set size $\times$ phase interaction, the apparently larger effect of memory set size in Phase 2 , did not reach significance $[F(3,6)=3.68, p>.05]$. A Newman-Keuls post hoc test with an alpha of .05 revealed two homogeneous subsets of memory set size scores: lower accuracy $(9,5)$ and higher accuracy $(2,3,5)$.

\section{EXPERIMENT 5}

In the previous experiments, attempts to demonstrate proactive interference in situations in which information stored on one trial is carried forward, with interfering consequences, to a following trial were met with little suc- 

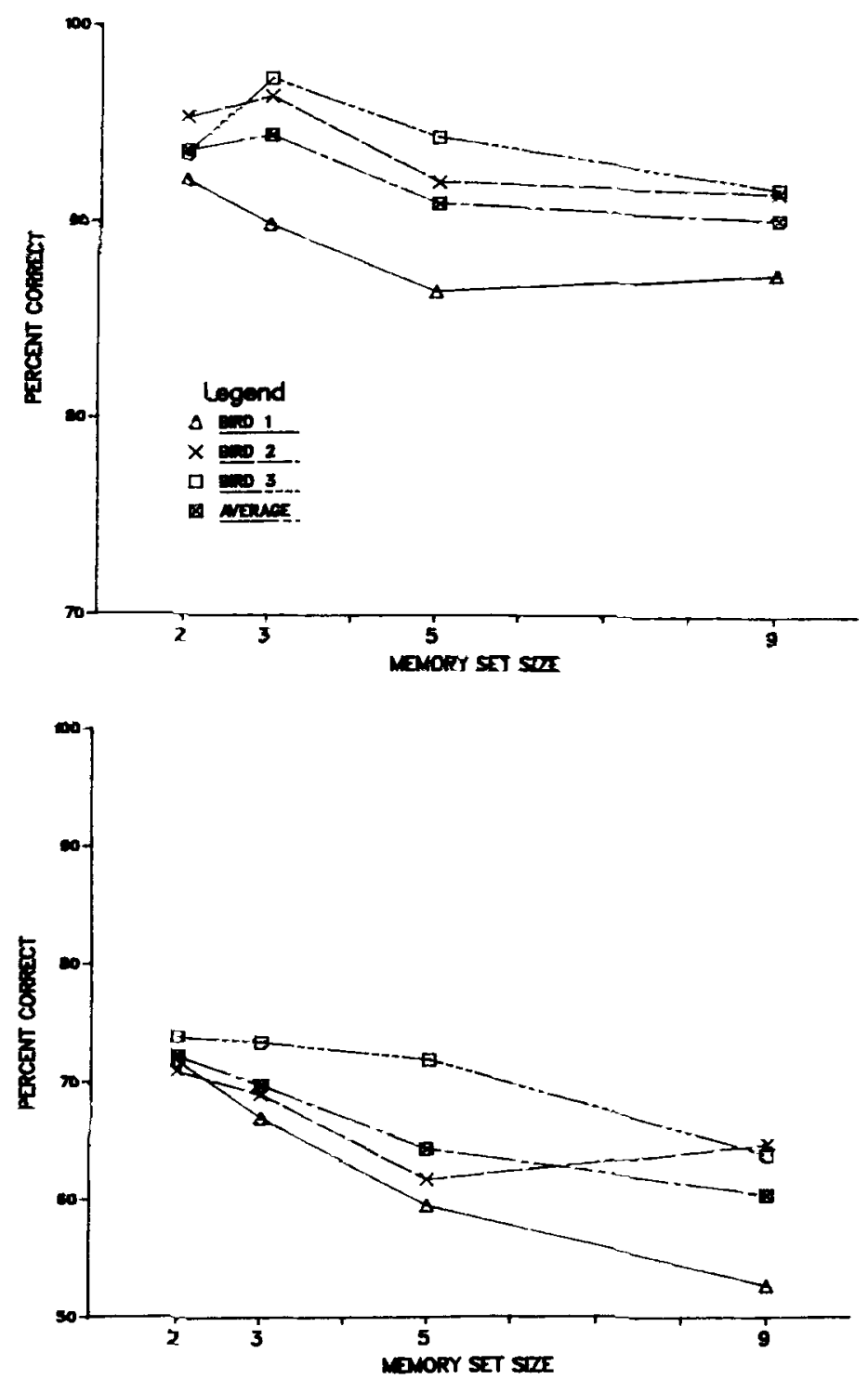

Figure 5. Matching accuracy for each pigeon as a function of memory set size when the delay was . 5 sec (top panel) or $3 \mathrm{sec}$ (bottom panel). Data are averages of 45 sessions (top panel) and 33 sessions (bottom panel).

cess. Proactive interference may also be manifested within a particular trial if stimuli other than the target (i.e., sample) stimulus are presented. Accordingly, in the present experiment, an attempt was made to demonstrate such intratrial proactive interference by presenting the distraction for a particular trial immediately before the sample presentation. On control trials, either the sample was repeated twice or no stimuli were presented before the sample.

\section{Method}

Subjecls and Apparatus. Five King pigeons that were experienced al delayed key location matching were lested in the apparatus used in the previous experiments.
Procedure. Each subject received approximately 10 sessions consisting of 60 trials eact. The intertrial interval was $20 \mathrm{sec}$ and the retention interval was $1 \mathrm{sec}$. Three types of trials occurred with equal probability and in a random order. On one type of trial (blank trials), the sample was simply presented for $1.5 \mathrm{sec}$. On a second type, the sample was presented for $1.5 \mathrm{sec}$ and then, after $.2, .5$, or $3.5 \mathrm{sec}$ (the interstimulus interval), the sample was presented for a second time, again for $1.5 \mathrm{sec}$. On the remaining type of trial, the distractor that had been randomly selected for that trial was presented for $1.5 \mathrm{sec}$, again $.2, .5$, or $3.5 \mathrm{sec}$ before the 1.5 -sec presentation of the sample.

\section{Results}

Figure 6 shows matching accuracy when nothing (blank), the sample, or the distractor preceded the not- 
BIRD 1

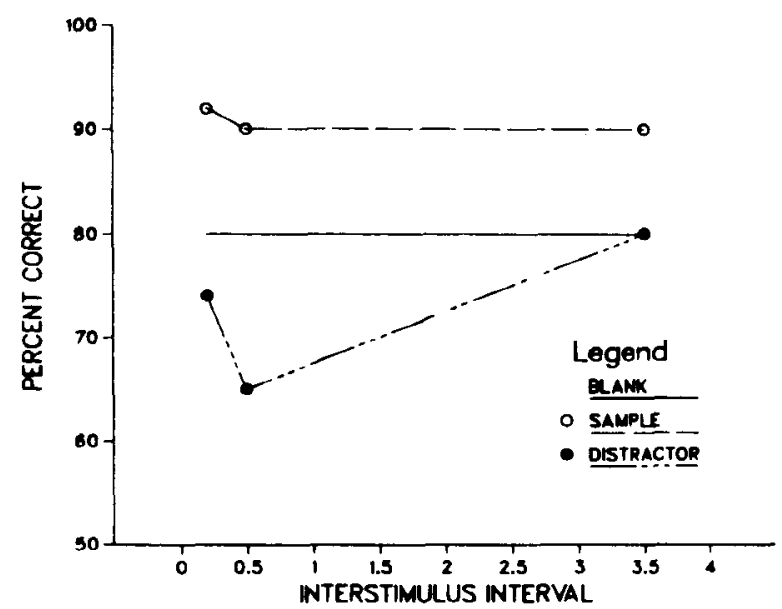

BIRD 2

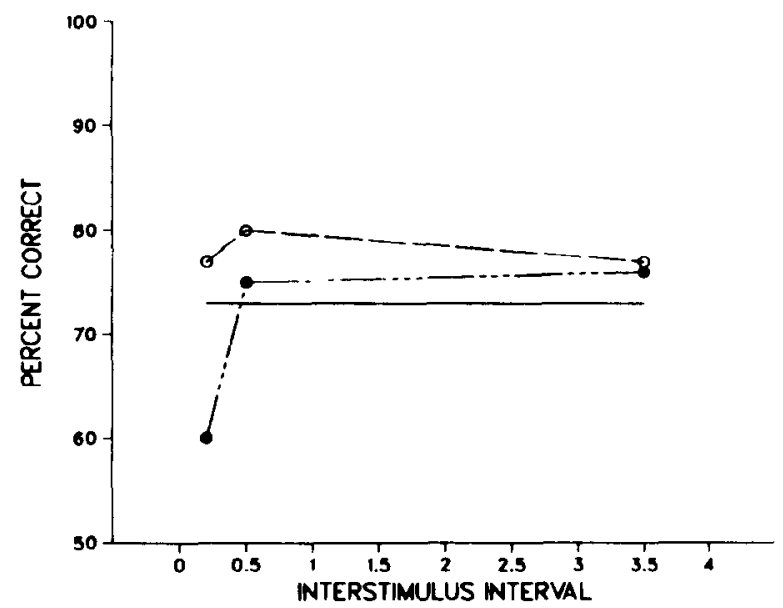

BIRD 3

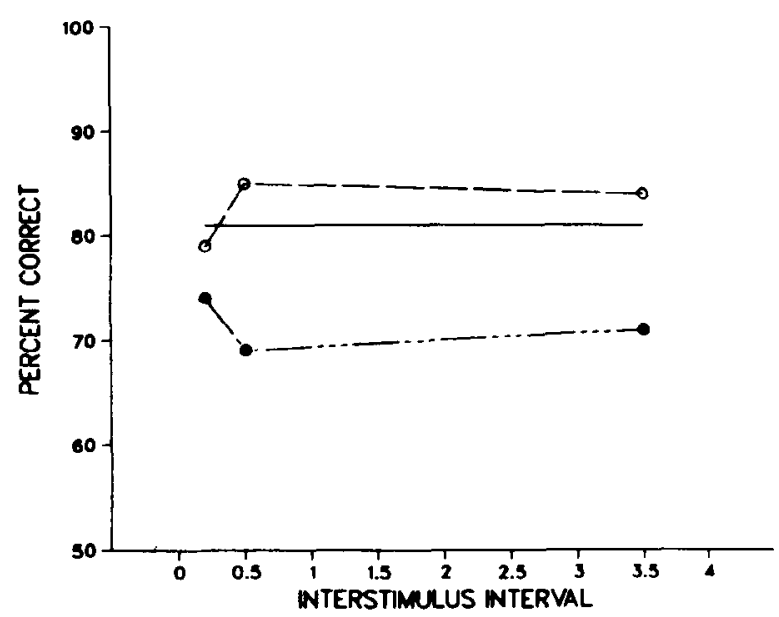

BIRD 4

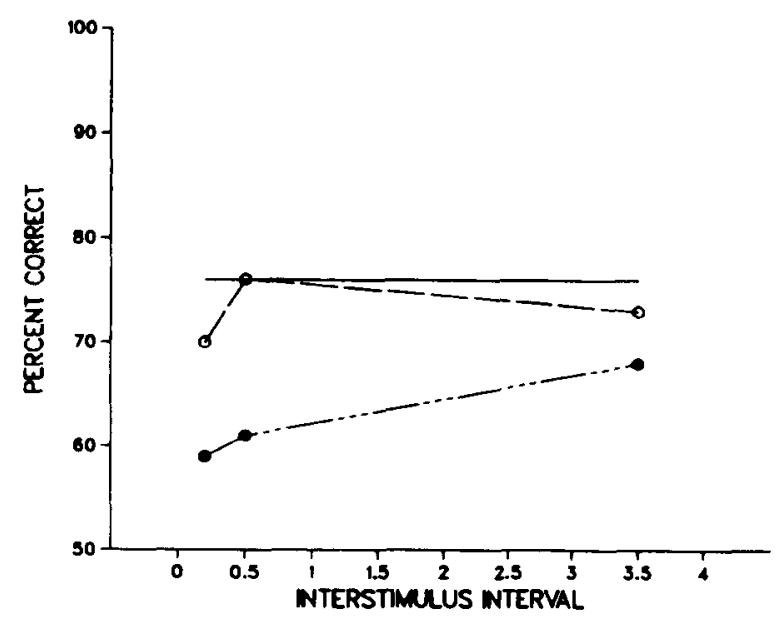

BIRD 5

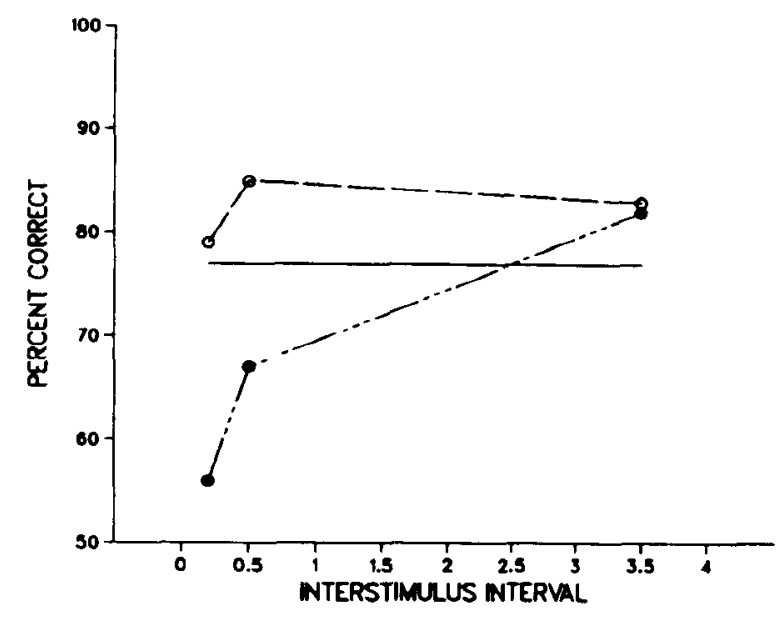

AVERAGE

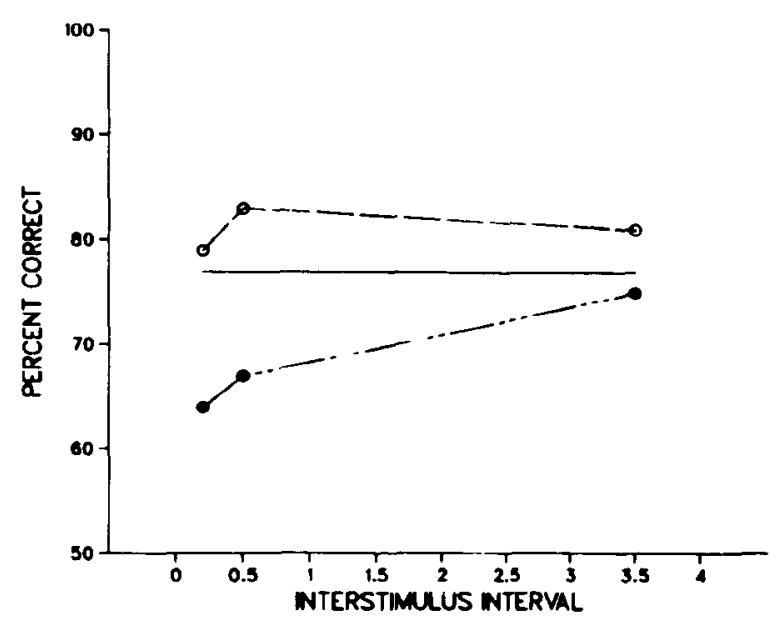

Figure 6. Matching accuracy for each pigeon as a function of whether nothing (blank), the sample, or the distractor was presented $.2, .5$, or $3.5 \mathrm{sec}$ before the sample. Data are averages over all sessions. 
mal sample presentation. Two-sample presentations sometimes facilitated matching relative to one-sample (i.e., blank) trials. Presenting the distractor prior to the sample had a clearly deleterious effect on matching accuracy, but only with very short $(.2$ or $.5 \mathrm{sec})$ interstimulus intervals for most subjects.

These observations were confirmed in a stimulus (blank, sample, or distractor) $\times$ interstimulus interval repeated measures analysis of variance. (Blank trials were made into a dummy variable by randomly selecting one-third of the trials for each interstimulus interval.) The stimulus $\times$ interstimulus interval interaction was significant $[F(4,16)=4.48, p<.025]$, as was the main effect of stimulus $[F(2,8)=22.97, p<.001]$. The main effect of interstimulus interval was not significant $[F(2,8)=.91$, $p>.05]$. A post hoc Newman-Keuls test $(\alpha=.05)$ revealed that distractor trials only at interstimulus intervals of .2 and $.5 \mathrm{sec}$ were different from the remaining scores.

\section{GENERAL DISCUSSION}

The results of Experiment 5 demonstrated that pigeons' short-term spatial memory is affected by proactive interference, albeit that the time course of this interference is very short. A clear implication of these results is that, although proactive interference in pigeons' short-term memory for key location is demonstrable, it does not seem to be a factor affecting performance with conventional trial parameters.

The failure to obtain proactive interference using intertrial manipulations may have been due to the fact that the intertrial intervals employed typically exceeded the pigeons' retention span. Wilkie and Summers (1982) reported that pigeons could not retain key location information for $8 \mathrm{sec}$. Thus, the absence of proactive interference may be accounted for by the fact that the intertrial intervals were normally longer than this value. The viability of this account, however, must be questioned by the observation that significant proactive interference in the intratrial procedure was found with interstimulus intervals of .2 and $.5 \mathrm{sec}$ but not with $3.5 \mathrm{sec}$ : Most pigeons retain key location information for at least 3 or $4 \mathrm{sec}$. Thus, proactive interference sometimes seems to be absent when conflicting information occurs within a period shorter than the normal retention interval before the target stimulus.

The present results are consistent with a "working memory" (Honig, 1978; Olton, 1978) model of pigeons' short-term spatial memory. According to such a model, information about the sample is stored in a limitedcapacity, resetable memory that is analogous to the temporary memory in the common electronic calculator. A key characteristic of this model is that it is dichotomous: Either information is in storage or the memory is cleared. Olton (1978) hypothesized that working memory is cleared at the end of each trial. Consequently, according to this model, there should be no interference between Trial $n-1$ and Trial $n$. The findings that having the sample from
Trial $n-1$ appear as the distractor on Trial $n$ did not adversely affect matching, that matching accuracy was no worse for smaller memory set sizes, and that there was no decline in accuracy over trials within a session are all consistent with this type of model. So, too, is the finding that proactive interference is produced by intratrial manipulations. Because memory is not cleared until the end of the trial, conflicting information presented during a trial would be expected to produce interference. Support for this model must remain tentative, however, because we have not yet demonstrated that intertrial manipulation conducted at very short intertrial intervals (e.g., $.5 \mathrm{sec}$ ) does not produce proactive interference. Also, the present results seem equally consistent with Staddon's (1983) alternative to a resetable working memory model of spatial memory. Briefly, it is assumed, in his model, that animals encode two types of information-spatial and temporal-in the form of a place-time code. Whenever a spatial cue occurs, the temporal code associated with this place is reset to maximum value; the code then decays in a hyperbolic fashion over time. According to this type of model, the pigeon in the delayed matching of key location chooses the place for which the temporal trace value is at the highest. Errors arise when the pigeon cannot discriminate between the magnitude of the traces associated with the sample and distractor. In terms of this model, intratrial, but not intertrial, proactive interference would be expected if the temporal trace decayed rapidly (i.e., during a period of time shorter than the intertrial interval). Thus, Staddon's model, which nicely handles many of the known facts about rats' spatial memory in radial-arm maze tasks, may also be applicable to pigeons' short-term memory for key location.

\section{REFERENCES}

Brodigan, D. L., \& Peterson, G. B. (1976). Two-choice discrimination performance of pigeons as a function of reward expectancy, prechoice delay, and domesticity. Animal Learning \& Behavior, 4, 121-124.

Gilbert, S. G. , \& RICE, D. C. (1979). NOVA SKED II: A behavioral notation language utilizing the Data General Corporation real-time disk-operating system. Behavior Research Methods \& Instrumentation, 11, 71-73.

Grant, D. S. (1975). Proactive interference in pigeon short-term memory. Journal of Experimental Psychology: Animal Behavior Processes, 1, 207-220.

HoNIG, W. K. (1978). Studies of working memory in the pigeon. In S. H. Hulse, H. Fowler, \& W. K. Honig (Eds.), Cognitive processes in animal behavior (pp. 211-248). Hillsdale, NJ: Erlbaum.

OLsoN, D. J., \& MAKI, W. S. (1983). Characteristics of spatial memory in pigeons. Journal of Experimental Psychology: Animal Behavior Processes, 9, 260-280.

Olton, D. S. (1978). Characteristics of spatial memory. In S. H. Hulse, H. Fowler, \& W. K. Honig (Eds.), Cognitive processes in animal behavior (pp. 341-373). Hillsdale, NJ: Erlbaum.

RoberTs, W. A., Kraemer, P. J. (1982). Some observations of the effects of intertrial interval and delay on delayed matching to sample in pigeons. Journal of Experimental Psychology: Animal Behavior Processes, 8, 342-353.

Roberts, W. A., \& VAN VEldhuizen, N. (1985). Spatial memory in pigeons on the radial arm maze. Journal of Experimental Psychology: Animal Behavior Processes, 11, 241-260. 
Smith, J. P., Attwood, J. C., \& Niedorowski, L. (1982). Delayed choice responding by pigeons when the correct response is not predictable from the sample stimulus. Journal of the Experimental Analysis of Behavior, 37, 57-63.

Staddon, J. E. R. (1983). Adaptive behavior and learning. Cambridge: Cambridge University Press.

WILkIE, D. M. (1983a). Pigeons' spatial memory: II. Acquisition of delayed matching of key location and transfer to new locations. Joumal of the Experimental Analysis of Behavior, 39, 69-76.

WILKIE, D. M. (1983b). Pigeons' spatial memory: III. Effect of distractors on delayed matching of key location. Joumal of the Experimental Analysis of Behavior, 40, 143-151.
WILKIE, D. M. (1984). Pigeons' spatial memory: IV. Effects of intertrial interval manipulations on delayed matching of key location. Canadian Journal of Psychology, 38, 178-195.

Wilkie, D. M., \&ummers, R. J. (1982). Pigeons' spatial memory: Factors affecting delayed matching of key location. Journal of the Experimental Analysis of Behavior, 37, 45-56.

Wilkie, D. M., Summers, R. J., \& SPETCH, M. L. (1981). Effect of delay-interval stimuli on delayed symbolic matching to sample in the pigeon. Journal of the Experimental Analysis of Behavior, 35, 153-160.

WorshaM, R. W. (1975). Temporal discrimination factors in delayed matching-to-sample task in monkeys. Animal Learning \& Behavior, 3, 94-97.

(Manuscript received November 12, 1985; revision accepted for publication April 9, 1986.) 